\title{
Pavan Duggal:
}

\section{International Conference on Cyberlaw, Cybercrime \& Cybersecurity}

http://www.cyberlawcybercrime.com

\begin{abstract}
:
This article reports from the International Conference on Cyberlaw, Cybercrime $\&$ Cybersecurity $\left(17^{\text {th }} \& 18^{\text {th }}\right.$ NOVEMBER, 2016, New Delhi - www.cyberlawcybercrime.com). The Conference was addressed by more than 150 speakers backed by more than 80 supporters. It was a wonderful opportunity to network with international thought leaders under one roof.
\end{abstract}

\section{Agenda:}

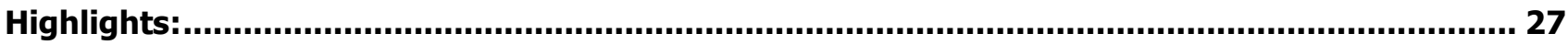

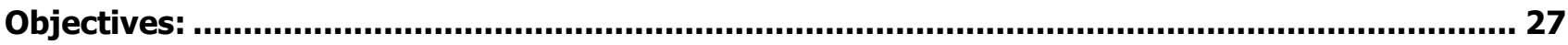

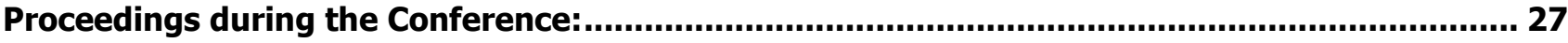

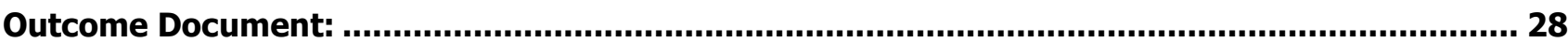

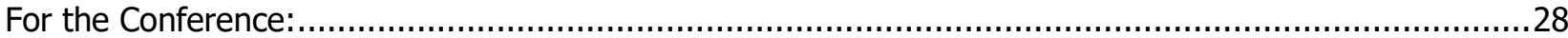

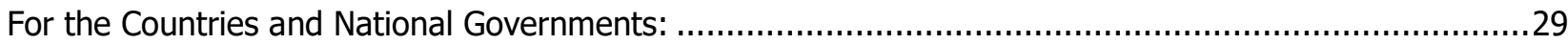

Photographs - international conference on cyberlaw, cybercrime \& cybersecurity 2016 ........... 30

\section{Author:}

Mr. Pavan Dugal:

- $\quad$ Advocate, Supreme Court Of India, President, Cyberlaws.Net, Head, Pavan Duggal Associates S-307, LGF, Greater Kailash-1, New Delhi, Delhi 110048 pavan@pavanduggal.com; pavanduggal@yahoo.com

- $\quad$ Expert and authority on Cyberlaw \& Mobile Law; acknowledged as one of the top four Cyber-lawyers in the world. More about the Author is available at www.pavanduggal.com and http://www.linkedin.com/in/pavanduggal 


\section{Highlights:}

- Conference was addressed by more than 150 speakers

- Conference having more than 80 supporters

- Wonderful opportunity to network with international thought leaders under one roof

\section{Objectives:}

The objectives of the International Conference on Cyberlaw, Cybercrime \& Cybersecurity are as follows:-

- The International Conference on Cyberlaw, Cybercrime \& Cybersecurity will look at the emerging legal, policy and regulatory issues pertaining to cyberspace and cybercrimes.

- To identify the emerging Cyberlaw, Cybercrime \& Cybersecurity trends and jurisprudence impacting cyberspace in today's scenario.

- To create far more awareness about the newly emerging kinds of cybercrimes that are impacting all stakeholders in the digital and mobile ecosystem.

- To identify the areas in cyber crimes where Cyberlaw needs to be further evolved so as to meet with the expectations and needs of the relevant stakeholders of the digital and mobile ecosystem.

- To work in the direction of creating an international network of cybercrimes and cyber-legal professionals which could then be an important voice in the further development of Cyberlaw, Cybercrime \& Cybersecurity jurisprudence across the world.

- Cybercrimes are now beginning to impact corporates in their new avatar. What are the major international Cyberlaw, Cybercrime \& Cybersecurity trends? What kind of new manifestations of cybercrimes are beginning to emerge that corporates need to be careful of? What international best practices need to be kept in mind by corporates for protecting themselves from being victims of Cybercrimes? What kind of overall anti-Cybercrime strategies do corporates need to have in place? These and a variety of other issues are sought to be addressed in the International Conference on Cyberlaw, Cybercrime \& Cybersecurity.

\section{Proceedings during the Conference:}

The International Conference on Cyberlaw, Cybercrime \& Cyber Security 2016 aimed to examine and analyze the emerging Cyberlaw, Cybercrime and Cybersecurity trends of today's times. The International Conference was attended by various international delegates and speakers as also representatives from the national Diaspora representing the stakeholders in the digital ecosystem and alive web. About 600 international and national delegates and attendees from the corporate and government sector participated in the International Conference on Cyberlaw, Cybercrime \& Cybersecurity.

The International Conference had more than 150 distinguished speakers and participants, which came from 39 different nations to address the conference.

The International Conference on Cyberlaw, Cybercrime \& Cybersecurity was supported by more than 80 international and national organizations. These would include UNESCO, UNODC, ITU in the UN Family, as also by Council of Europe, Europol Cybercrime Centre, Interpol, Internet Corporation for Assigned Names \& Numbers (ICANN), Internet Society, World Federation of Scientists, International Association of Prosecutors, Global 
Prosecutors E-Crime Network, Asia Cloud Computing Association, Ministry of Electronics \& Information Technology, Government of India, Ministry of Law \& Justice, Government of India.

The conference was inaugurated by Hon'ble Mr. Justice Dipak Misra, Judge, Supreme Court of India. In his inaugural address, Hon'ble Mr. Justice Dipak Misra pointed out that cyber crime had increased "proportionately" with the increase in mobile and internet penetration in the country. He further pointed out that there is need for international bondage which shall have the singular aim to preserve cyber security. The governments and stakeholders need to be more flexible. There is also need to develop jurisprudential principles concerning cyber law. The Conference was addressed by Ms. Aruna Sundarajan, Secretary, Ministry of Electronics \& Information Technology, Government of India. In her speech, Ms. Aruna Sundarajan stated that India is "leapfrogging" to use digital technology due to lack of "conventional infrastructure". In addition, Mr. Suresh Chandra, Secretary, Ministry of Law \& Justice, Government of India had also addressed the Conference. The conference was also addressed by Dr. Indrajit Banerjee, Director, UNESCO as also by Dr. Henning Wegener, World Federation of Scientists.

The Conference Director Mr. Pavan Duggal focused on the need for the countries ask to make the reporting of cyber security breaches as mandatory. He highlighted the need for cyberlaw jurisprudence to grow so as to represent the aspirations of all stakeholders in the digital and mobile ecosystem. He also spoke about the emerging issue of attribution of cybercrime activities and challenges raised by Internet jurisdiction and connected legalities.

\section{Outcome Document:}

The participants of the conference approved the distinctive Conference Outcome Document. By means of the said Conference Outcome Document, the participants of the conference called upon the conference to take variety of steps in the coming year. In addition, the Conference Outcome Document further called upon national governments and nation states to take various steps for promoting the cause of Cyberlaw, Cybercrime and Cybersecurity. The following important key decisions have been arrived at the conference.

\section{For the Conference:}

- To take thought leadership in contributing towards evolving Cyberlaw jurisprudence

- To work and contribute towards evolving cyber security law jurisprudence by coming up with common denominators and principles which are accepted by nations concerning protection and preservation of cyber security

- To work on collating principles of cyber security law jurisprudence in collaboration with distinct thought leaders and international stakeholders including International Commission on Cyber Security Law

- To work with the international organizations and stakeholders for the purposes of coming up with legal frameworks on how to deal with the challenges posed by Security, Privacy and Freedom

- To collate international best practices concerning Cyberlaw by working with all relevant stakeholders for the benefit of the entire community and comity of nations

- To work towards harmonizing principles on Cyberlaw globally to include ethical values, virtues and balancing conflicting value perceptions in all instruments to strengthen cyber laws, aligned with international cooperation principles

- To tie-up with international stakeholders and collate international best practices concerning emerging jurisprudence concerning Cyberlaw, Cybercrime and Cybersecurity and further to engage in distinct 
deliberations with stakeholders to help collate common universally accepted principles concerning Cyberlaw, Cybercrime and Cybersecurity

- To work for and contribute towards the respect of International Law enshrining the Freedom of Opinion and Expression

- To work on issues concerning Darknet jurisprudence as also legal, policy and regulatory issues concerning Darknet

- To strengthen the Permanent Standing Committee on Cyberlaw, Cybercrime \& Cyber Security, recommended by the 2014 conference

\section{For the Countries and National Governments:}

- To work together towards evolving international solutions to deal with the legal challenges presented by jurisdiction and attribution on the Internet

- To mandate provisions for reporting cybercrimes and breaches of cyber security by various stakeholders and further encourage them to come up with appropriate enforcement mechanisms to enforce such reporting

- To achieve the golden balance between protecting national interests, sovereignty, integrity and security on the one hand and the protection and preservation of individual liberty, rights and obligations on the other hand

- To have in place robust legal frameworks for protection and preservation of Critical Information Infrastructures and to promote information sharing between public and private sectors to protect critical assets from cyber security threats; To work in close interaction with all stakeholders in the cyber community as also space community at the inter-governmental level for increased global awareness of the need to protect space assets and space systems, including critical infrastructures as well as to encourage enhanced cooperation and coordination for finding and implementing common approaches to the protection of communications and space systems.

- To proactively deal with the issue of detection, investigation and prosecution of cybercrimes on an expeditious basis

- To work for a universal cyber penal law and internationally binding rules of cooperation in law enforcement, in order to close existing loopholes in the persecution of cyber criminals

- To participate actively in all international endeavors to extend International Law, and particularly the International Law of Conflict, to the requirements of the digital environment with a view to generate consensus rules of law and behavior limiting conflict and conserve cyber peace

- To introduce legal, policy, administrative and pragmatic frameworks as a priority towards establishing a safe and secure cyberspace and aid in its further development.

The conference participants urged that a united effort is necessary to be adopted by all stakeholders to maintain cyberspace that is safer, more resilient, and remains a source of tremendous opportunity and growth for years to come. 
Photographs - international conference on cyberlaw, cybercrime \& cybersecurity 2016

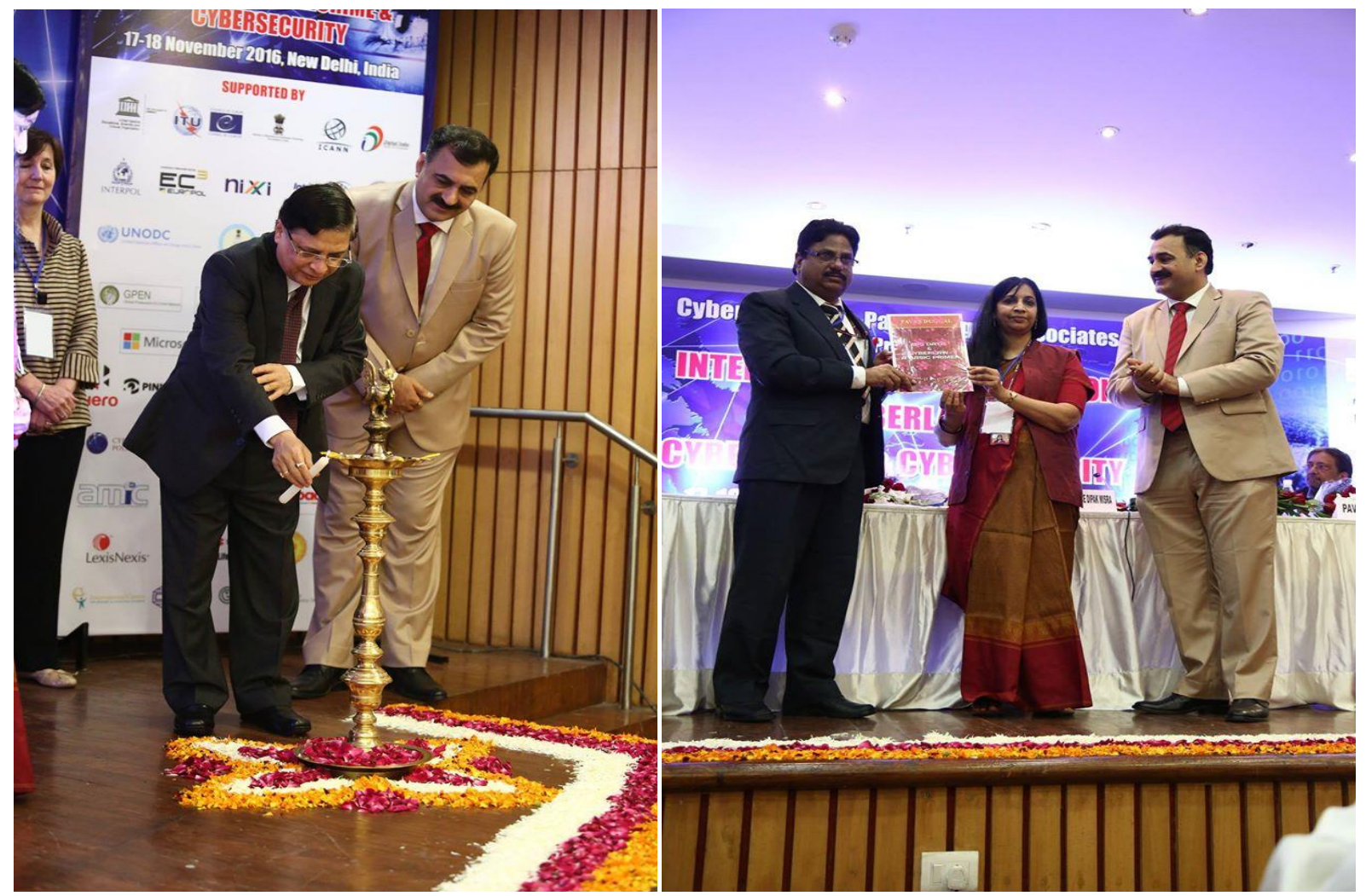

Hon'ble Mr. Justice Dipak Misra Judge, Supreme Court of India Inaugurating the Conference
Ms. Aruna Sundarajan, Secretary, Ministry of Electronics \& Information Technology,Government of India being Felicitated

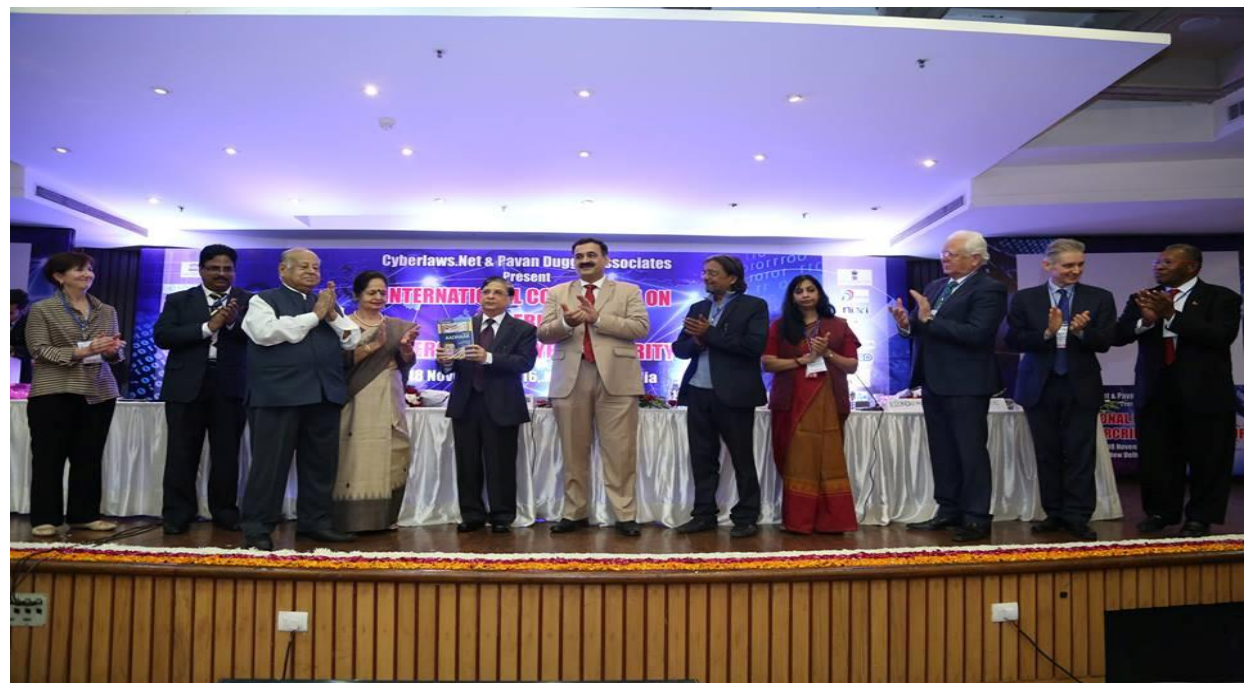

Release of the Book on "LAW ON AADHAR" authored by Mr. Pavan Duggal 


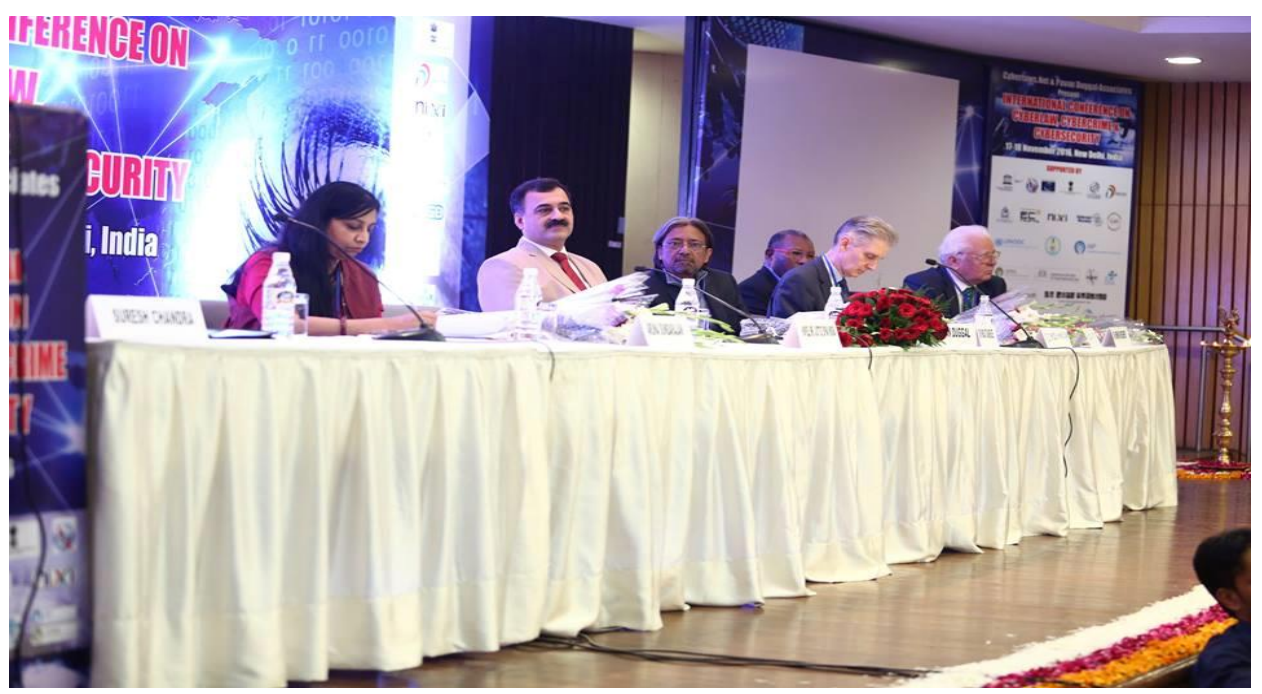

Inaugural Session in Progress

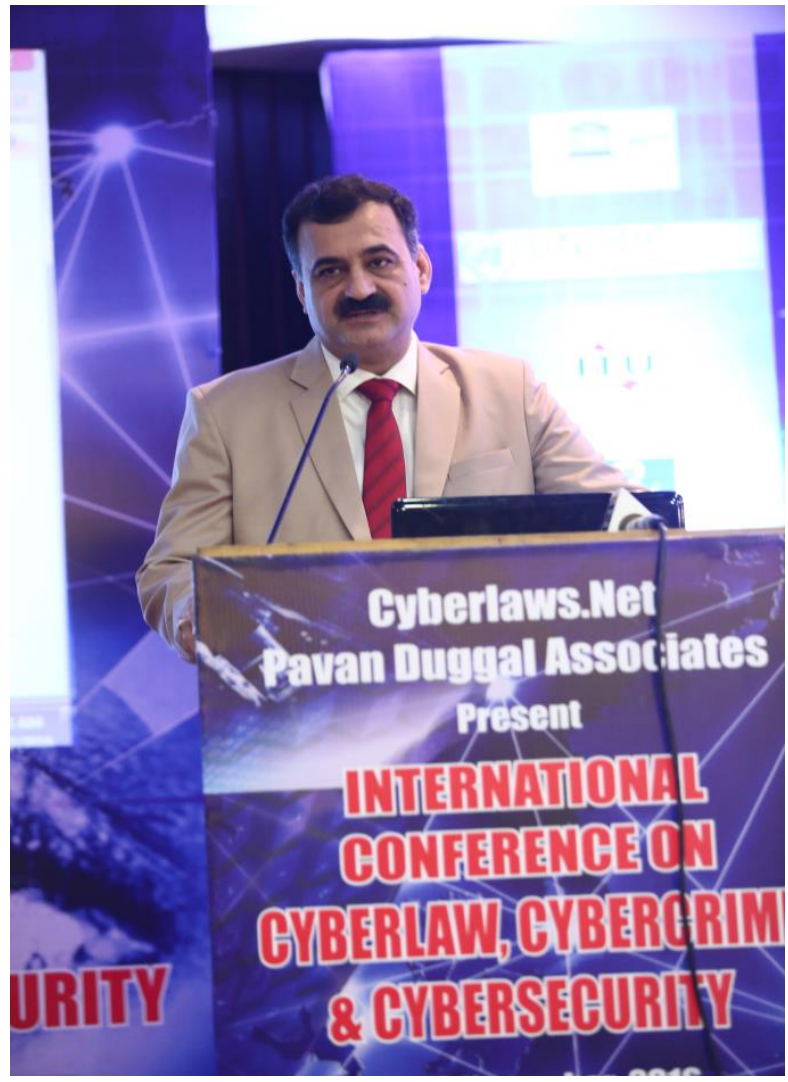

Mr. Pavan Duggal Addressing the Delegates 


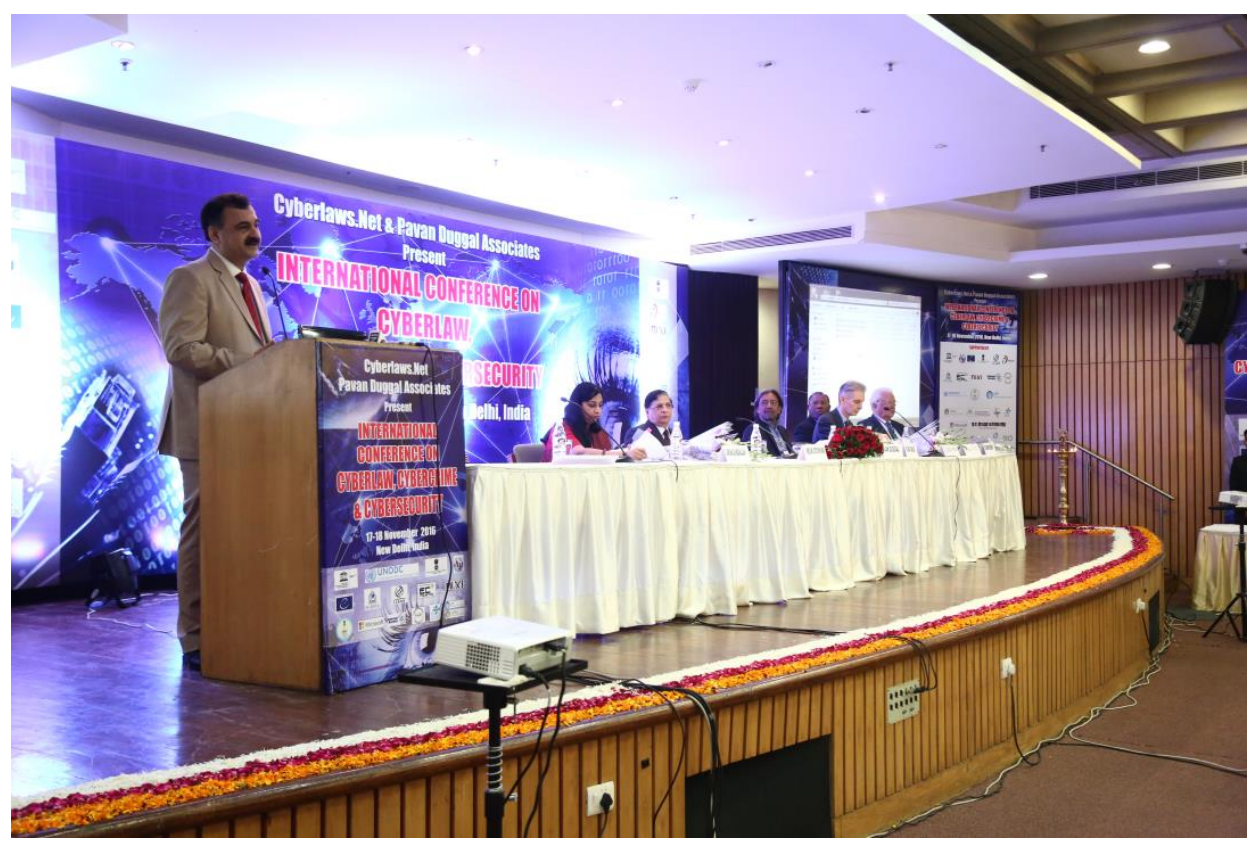

Mr. Pavan Duggal with Dignitaries on the Dias

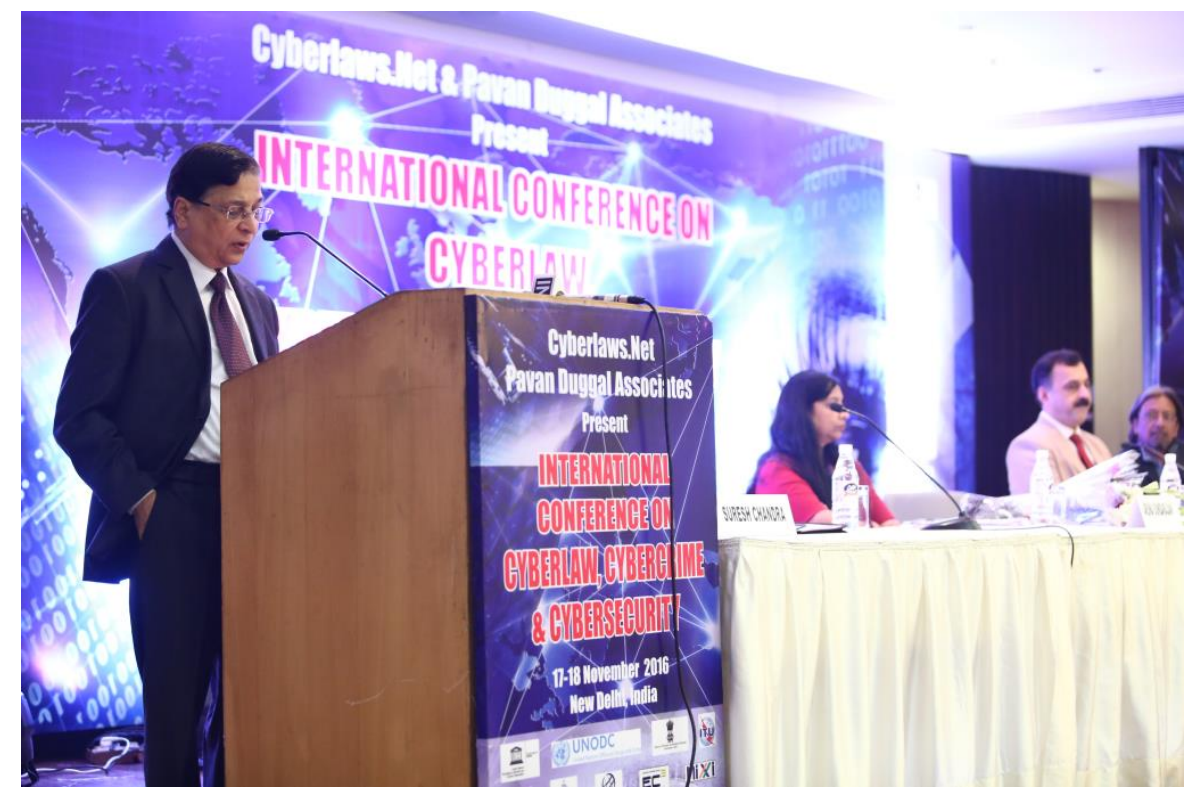

Hon'ble Mr. Justice Dipak Misra

Judge, Supreme Court of India delivering the Inaugural Address 